Research Article

\title{
Experimental Study on Structural Mechanics of Asphalt Pavement by Digital Speckle Correlation Methods
}

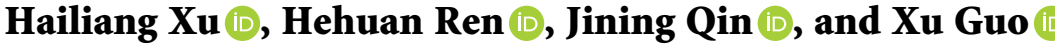 \\ School of Civil Engineering, North China University of Technology, Beijing 100144, China \\ Correspondence should be addressed to Hailiang Xu; hailiang_xu@126.com and Hehuan Ren; 13552701671@163.com
}

Received 7 September 2020; Revised 9 October 2020; Accepted 21 October 2020; Published 5 November 2020

Academic Editor: Zheng-Zheng Wang

Copyright (c) 2020 Hailiang Xu et al. This is an open access article distributed under the Creative Commons Attribution License, which permits unrestricted use, distribution, and reproduction in any medium, provided the original work is properly cited.

\begin{abstract}
The experiments on the structural mechanics of asphalt pavement were carried out by the digital speckle correlation method (DSCM). The digital speckle correlation method is used to collect experimental data. The displacement and strain values of each layer of the asphalt pavement structure are analyzed. The research showed that (1) the digital speckle correlation methods could accurately observe the displacement value and the strain value of the pavement structure. (2) The stress state of the pavement structure was greatly influenced by the interlayer effect. The vertical displacement changed suddenly between layers. The concentration phenomenon of the tension-compression strain and the shear strain appeared between layers. (3) The overloading situation seriously worsened the overall stress state of the pavement structure, especially at the bottom of the asphalt top layer and lower layer and at the top of the cement-stabilized crushed stone. The research results are of great significance to the structural design of heavy-duty roads.
\end{abstract}

\section{Introduction}

Vehicle load is the main factor affecting the service life of asphalt pavement and causing damage to pavement structure. The research on the mechanical properties of asphalt pavement structure under different load conditions mainly includes numerical simulation, theoretical calculation, and experimental research.

In terms of finite element numerical simulation, Liu et al. [1] used the BISAR3.0 numerical calculation software to calculate the stress and displacement under the contact of different base and surface layers of the asphalt pavement structure. Gao [2] established a dynamic finite element calculation model under traffic load to explore the relationship between subgrade dynamic response and influencing factors. In terms of theory, $\mathrm{Xu}[3,4]$ and Zhang [5] established a vertical-coupled dynamic model of heavy-duty vehicle-road-subgrade. They studied the dynamic interaction of moving heavy-duty vehicles, road structure, and subgrade under the excitation of road roughness. Mao et al. [6] established a theoretical model of mechanical friction strength between asphalt pavement layers based on fractal theory and analyzed the mechanical friction strength characteristics of the asphalt pavement with different grading structure layers. In the aspect of experimental research, Zhou et al. [7] obtained the change of strain between layers of the same material and different materials through the experiment of small-size interlayer bonding and analyzed the influencing factors of the interlayer strain conduction of the asphalt pavement. Wang [8] designed a fullscale pavement loop test to study the structural design and verification direction of more than ten kinds of typical pavement structures and explored the relationship between the mechanical properties of asphalt pavement and different materials. $\mathrm{Wu}$ [9] conducted a four-point fatigue bending test of the trabecular beam of the asphalt mixture. Xu et al. [10] used shear test and pull-out test to evaluate and rank the performance of five adhesive layer materials in terms of temperature change, freeze-thaw cycles, and adhesive layer oil aging. Chen et al. [11] used shear stress and pull-out stress testing equipment to test the maximum stress of the test samples and compared the asphalt pavement formed after the pits were treated on the semirigid cement-stabilized gravel base with the traditional interlayer treatment 
methods. Safavizadeh et al. [12-14] verified the reliability of DIC technology in the fatigue and fracture testing of asphalt concrete.

Limited by the means of measurement and testing, the test mainly uses buried pressure box, asphalt strain gauge, and axis gauge. Although these test methods can reflect the overall stress status of the pavement structure, there are some unfavorable factors such as the limited number of layout points, the inconvenience of the test originals, and the high accuracy of the test quality.

Aiming at the above problems in the experimental research, this paper uses the new digital speckle observation correlation method (DSCM) to test the mechanical properties of asphalt pavement structure under different loading conditions.

\section{Basic Principles of Digital Speckle Correlation Methods}

The digital speckle correlation method (DSCM) was independently proposed by Yamaguchi [15] in Japan and Peter and Ranson et al. [16] in the United States in the early 1980s. It mainly uses optical observation and postimage processing. This method has the advantages of global observation, adjustable range accuracy, noncontact mode, easy operation, and reliable data.

2.1. Correlation Function of Digital Speckle. In graphics processing, grayscale is the carrier of graphics data (grayscale is the speckle field formed by black-white spots or whitespotted black spots). DSCM establishes the correlation function between the gray level of the image before deformation and the gray level of the image after deformation and uses the calculation software to convert the graphic data into digital data. The general standardized correlation function [17-20] commonly used in DSCM is shown as follows:

$$
C(u, v)=\frac{\sum_{x=-M}^{M} \sum_{y=-M}^{M}[f(x, y) g(x+u, y+v)]}{\sqrt{\sum_{x=-M}^{M} \sum_{y=-M}^{M} f^{2}(x, y)} \sqrt{\sum_{x=-M}^{M} \sum_{y=-M}^{M} g^{2}(x+u, y+v)}},
$$

where $f(x, y)$ is the grayscale function of the reference image at a certain point $(x, y)$ before deformation and $g(x+$ $u, y+v)$ is the gradation function of the target image at the point $(x+u, y+v)$ after deformation, and the correlation coefficient $C(u, v)$ ranges from $[0,1]$. The existing research [14] normalizes the correlation function by the mean square error of gray and can highlight the mutation value of the correlation function in the coefficient matrix (that is, the normalized covariance correlation function).

2.2. Digital Speckle Correlation Search Method. In the grayscale pictures taken by the camera, the grayscale search algorithm is also crucial. The classical gray search methods include the thickness search method, the cross search method, the mountain climbing search method, the neighborhood search method, and the Newton-Raphason partial differential correction method.

As for the cross search method used in this experiment, since it reduces the two-dimensional search method to the one-dimensional search method, the search time is reduced, and the search efficiency is improved. The specific search process is as follows: starting from the reference image point $\mathrm{A}$, several points equidistant from point $\mathrm{A}$ are made on the $x$ and $y$ axes, and the correlation $C(u, v)$ coefficients of these points are calculated to find point $B$ of the maximum value in the direction of the single coordinate axis. Then, starting from point $\mathrm{B}$, point $\mathrm{C}$ where the correlation coefficient $C(u, v)$ is the largest is found on the $x$-axis, and then point $C$ is the peak point at which the final correlation coefficient is the largest. A schematic diagram of the cross search method is shown in Figure 1.

\section{Production of Test Model for the Pavement Structure}

The structural test piece is prepared by a layer of asphalt (top, middle, and lower layers) and a layer of cement-stabilized macadam (top and lower base layers). The parameter settings of each layer are shown in Table 1. After each layer was prepared for bonding, an artificial speckle field was sprayed on the observation surface.

Cement-stabilized macadam layer was prepared according to 5\% cement-stabilized macadam mixture ratio. It was prepared according to the mass ratio of cement: coarse aggregate $:$ fine aggregate $:$ sand $:$ water $=113: 906: 566: 793$ : 112 , and three sets of test pieces were prepared. For the preparation of the asphalt structural layer material, the commercial asphalt concrete materials AC-13, AC-20, and AC-25 are, respectively, poured into the asphalt mold and then compacted, allowed to stand, demoulded, and maintained.

For the pavement of each layer of the structure, firstly the cement mortar is equipped with a cement : sand ratio of $1: 3$ to connect the cement-stabilized layer, the cement mortar is used to smooth the top surface of the water-stable base and the upper and lower water-stable bases are connected. To connect the asphalt layers, first water-based bitumen permeable layer oil is used to wet the bottom layer, and then oily 70\# bituminous layer oil is evenly applied, and the two bitumen layers are combined and statically pressed for $12 \mathrm{~h}$. 


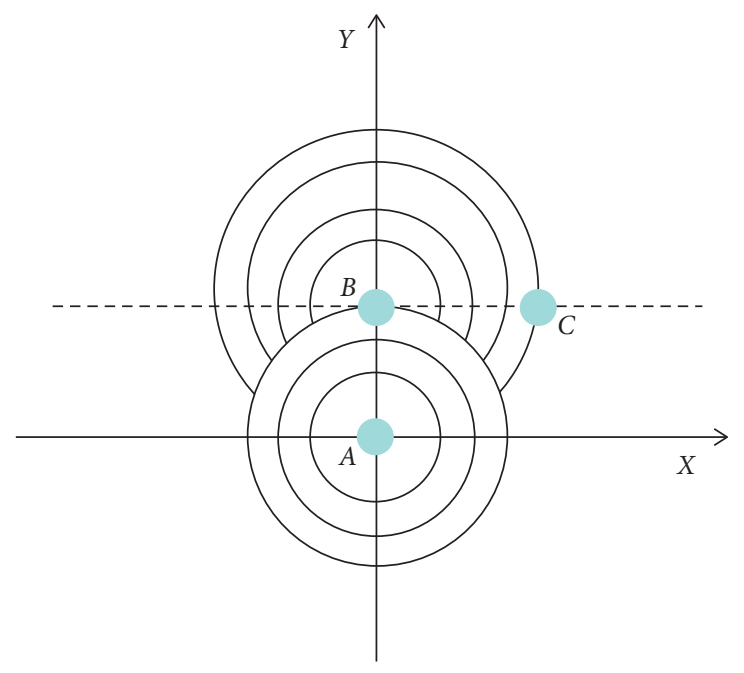

Figure 1: Rood pattern search.

TABLE 1: Structure layer parameters.

\begin{tabular}{|c|c|c|c|c|}
\hline Position & Material & Length $(\mathrm{m})$ & Width (m) & Thickness (m) \\
\hline Top layer of asphalt & AC-13 & 0.8 & 0.3 & 0.04 \\
\hline Middle layer of asphalt & AC- 20 & 0.8 & 0.3 & 0.05 \\
\hline Lower layer of asphalt & AC- 25 & 0.8 & 0.3 & 0.07 \\
\hline Upper base layer of cement-stabilized macadam & Cement-stabilized macadam & 0.8 & 0.3 & 0.2 \\
\hline Lower base layer of cement-stabilized layer & Cement-stabilized macadam & 0.8 & 0.3 & 0.2 \\
\hline
\end{tabular}

The artificial speckle field was sprayed at a center area of the test piece of $20 \times 56 \mathrm{~cm}$. First black lacquer is used to make a primer. After the black lacquer is dried, white spots are evenly sprayed with white lacquer. The speckle field is the analysis range. The overall structure is shown in Figure 2.

The testing system consisted of the WAW-600 electrohydraulic servo universal testing machine and two CCD cameras, as shown in Figure 3. Three-stage loading (static load) was used during the test, which were standard load $(0.7 \mathrm{MPa}), 50 \%$ overload $(1.05 \mathrm{MPa})$, and $100 \%$ overload (1.4 MPa). The load was symmetrically loaded on both sides of the center line of the test piece, and the loading range was $20 \times 56 \mathrm{~cm}$.

\section{Mechanical Analysis of the Pavement Structure}

According to the existing research results [17], the failure forms of pavement structure corresponding to the mechanical indexes are shown in Table 2.

According to the contents in the table, the analysis indexes of the pavement structure, including vertical displacement (deflection value), vertical strain, and vertical shear strain, are selected as the main analysis indexes for the main forms of structural failure.

4.1. Vertical Displacement Analysis of Structural Floor. Vertical displacement (deflection value) of the pavement structural layer is an important reference value in pavement structural design. In the test process, the vertical displacement cloud maps of some pavement structural layers under different loads are shown in Figures 4 6.

The displacement cloud diagram data are read, and the representative vertical displacement value on the center line in the diagram is selected for specific analysis, as shown in Figure 7.

As can be seen from Figure 7,

(1) The displacement between layers of pavement structure is discontinuous, and there is a sudden change in the displacement value at the junction between layers, which is greatly different from the assumed displacement continuity condition in most current numerical calculation models. Taking 100\% overload as an example, the mutation values of the upper, middle, and lower surface layers of asphalt are 9.2 (unit: the same as below $0.01 \mathrm{~mm}$ ) and 3 $(0.01 \mathrm{~mm})$ respectively, and the mutation amplitude reaches $23.3 \%$ and $10.3 \%$. The same rule is also observed under other loads, as shown in Table 3.

(2) The vertical displacement value within the asphalt surface layer decreases gradually with the increase of the structure depth, but the displacement value between the asphalt layer and the water-stable layer increases abruptly. Similarly, taking 100\% overload as an example, the displacement value of the bottom of the asphalt layer is $25.1(0.01 \mathrm{~mm})$, while the displacement value of the top layer above the waterstable layer is $33.5(0.01 \mathrm{~mm})$, and the added value of displacement is $8.4(0.01 \mathrm{~mm})$, with an increase of $33.27 \%$. 


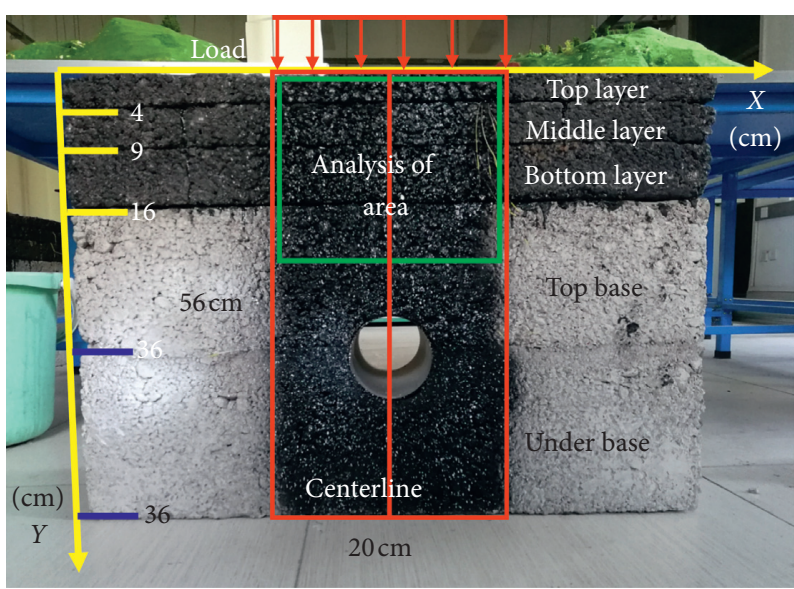

Figure 2: The whole structure.

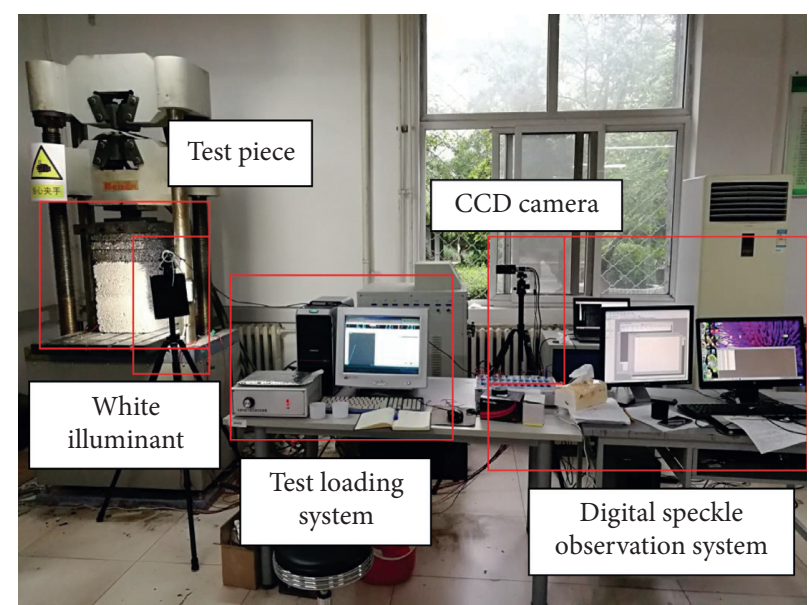

Figure 3: Arrangement of the site experiment.

TABLE 2: The form of structure collapse.

\begin{tabular}{lcc}
\hline Mechanics index & Mechanical symbol & Pavement structure failure mode \\
\hline Vertical displacement & $U y$ & Vertical deformation \\
Transverse stress & $\sigma_{x}$ & Cracks in the bottom layer caused by cracking \\
Vertical stress & $\sigma_{y}$ & The bottom of a U-shaped crack \\
Transverse shear stress & $\tau_{x z}$ & Both sides of the U-shaped dehiscence \\
Vertical shear stress & $\tau_{x y}$ & Lateral slip, rutting, side cracking \\
Longitudinal shear stress & $\tau_{y z}$ & Longitudinal slip \\
\hline
\end{tabular}

(3) It can be seen from Figure 7 that the abrupt change amplitude of displacement value between layers of pavement structure increases with the increase of load. That is to say, the greater the load is, the greater the influence of the interlayer effect will be.

(4) With the increase of load, the displacement value of each layer of the pavement shows an increasing trend, but the influence degree is the largest on the asphalt layer, followed by the base layer on the waterstabilized gravel. Therefore, for some heavy load roads, the thickness and strength of the asphalt layer above the pavement structure and the base layer on the water-stabilized gravel should be appropriately increased.

4.2. Pavement Structure Layer Strain Analysis. The strain index of the pavement structure layer is an important research content of pavement structure stress. Figures 8-10 show the strain cloud diagram of pavement structure under different loads obtained during the test.

The strain data observed in Figures 8 10 are arranged, and the strain data at the center line are selected for analysis, as shown in Figure 11. 


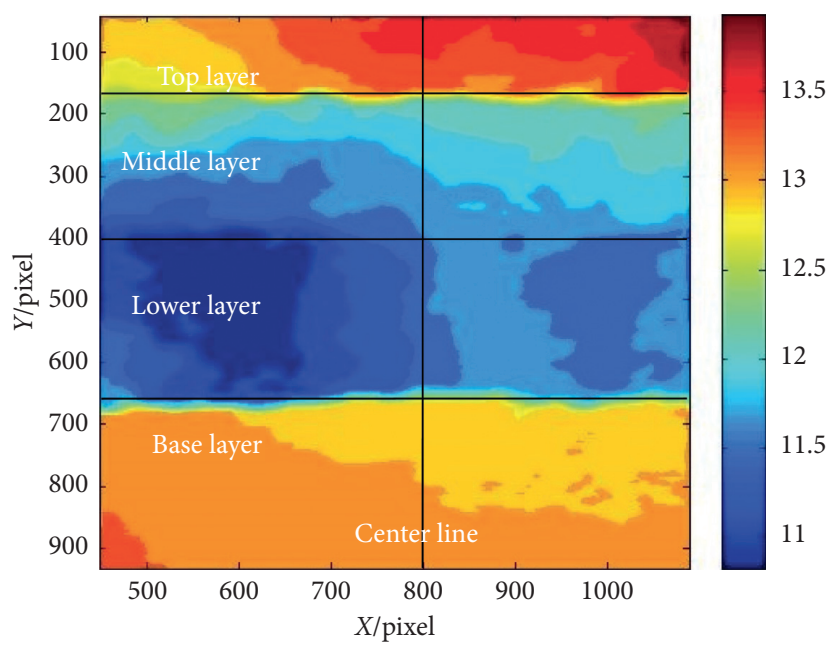

FIgURE 4: Vertical displacement cloud chart under standard load.

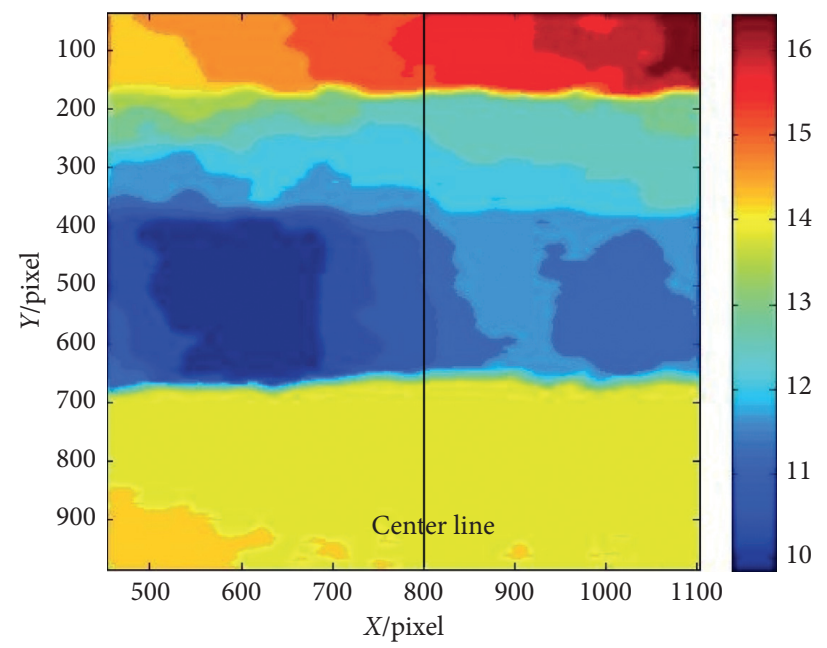

Figure 5: Vertical displacement under 50\% overload.

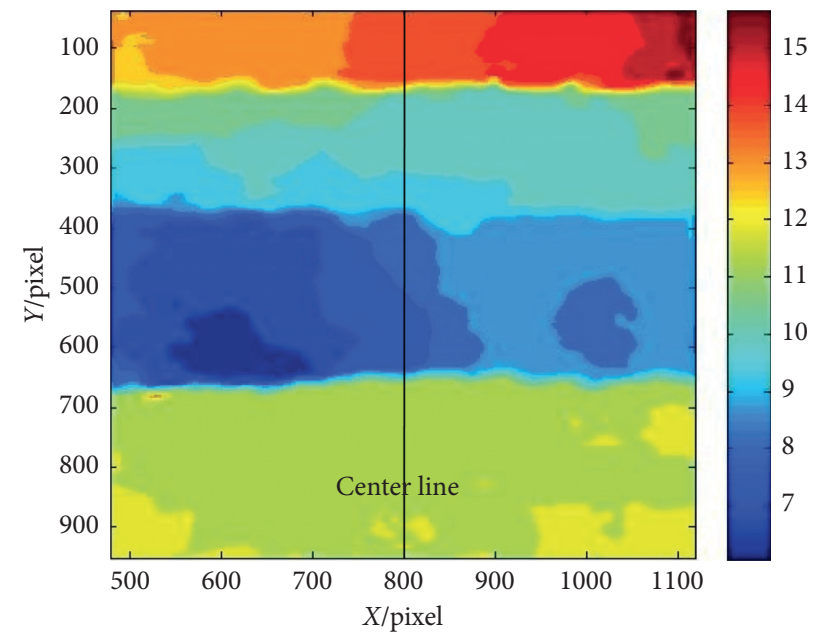

Figure 6: Vertical displacement under 100\% overload. 


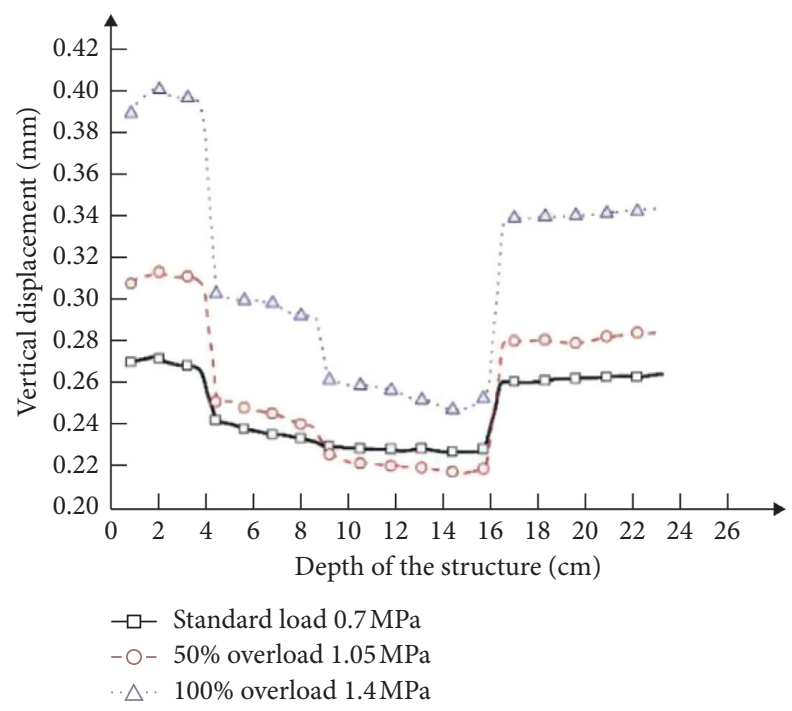

Figure 7: Vertical displacement line of the center line.

TABLE 3: Vertical displacement of structure interlayer.

\begin{tabular}{|c|c|c|c|c|c|c|}
\hline Working condition & \multicolumn{2}{|c|}{ Bottom of the upper layer } & \multicolumn{2}{|c|}{$\begin{array}{c}\text { Bottom of the middle } \\
\text { layer }\end{array}$} & \multicolumn{2}{|c|}{ Bottom of the lower layer } \\
\hline Unit: mm & \multicolumn{2}{|c|}{ Top of the middle layer } & \multicolumn{2}{|c|}{ Top of the lower layer } & \multicolumn{2}{|c|}{$\begin{array}{l}\text { Top of the cement- } \\
\text { stabilized layer }\end{array}$} \\
\hline \multirow{2}{*}{ Standard load } & 0.2670 & 0.2420 & 0.2319 & 0.2293 & 0.2274 & 0.2607 \\
\hline & \multicolumn{2}{|c|}{$-9.36 \%$} & \multicolumn{2}{|c|}{$-1.12 \%$} & \multicolumn{2}{|c|}{$14.65 \%$} \\
\hline \multirow{2}{*}{$50 \%$ overload } & 0.309 & 0.251 & 0.238 & 0.226 & 0.218 & 0.279 \\
\hline & \multicolumn{2}{|c|}{$-18.85 \%$} & \multicolumn{2}{|c|}{$-5.40 \%$} & \multicolumn{2}{|c|}{$27.87 \%$} \\
\hline \multirow{2}{*}{$100 \%$ overload } & 0.395 & 0.303 & 0.291 & 0.261 & 0.251 & 0.335 \\
\hline & \multicolumn{2}{|c|}{$-23.30 \%$} & \multicolumn{2}{|c|}{$-10.35 \%$} & \multicolumn{2}{|c|}{$33.27 \%$} \\
\hline
\end{tabular}

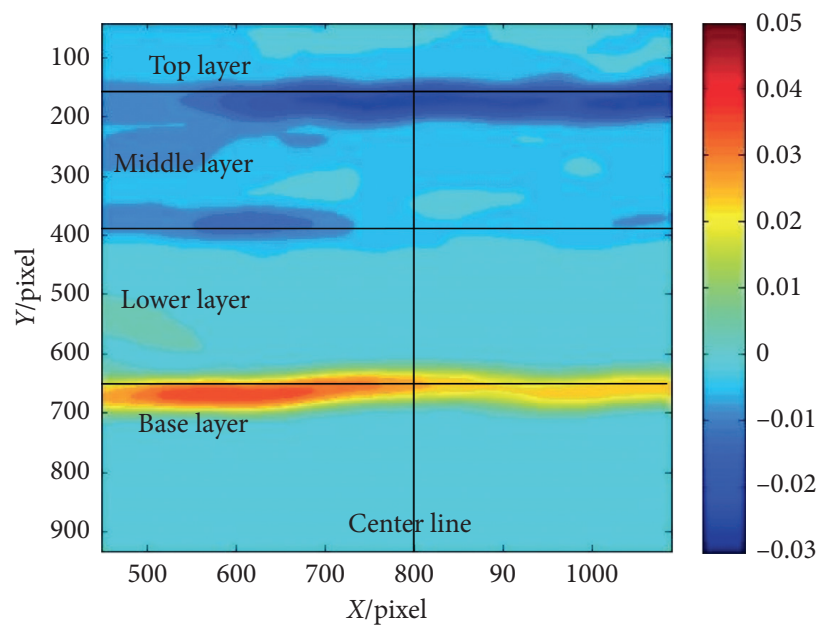

Figure 8: Vertical strain under standard load.

From Figures 8 to 11, it can be intuitively seen that the overall stress of the pavement structure is dominated by compression, but the bottom of the asphalt underlayer is under tension. Meanwhile, it can be seen from Figure 11 that (1) the phenomenon of strain concentration appears at the bottom of each layer of pavement structure, that is, the maximum strain of each layer appears at the bottom of the layer; (2) under different load conditions, the maximum compressive strain appears at the bottom of the layer above the asphalt, and the maximum tensile strain appears at the bottom layer below the asphalt. This is due to the upward bending of the pavement structure. Moreover, the variation 


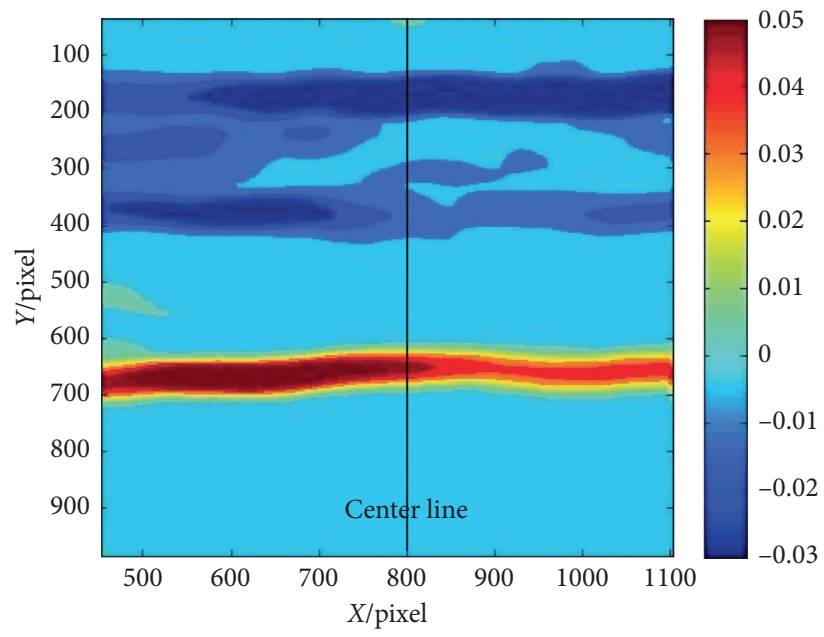

FIGURE 9: Vertical strain under $50 \%$ overload.

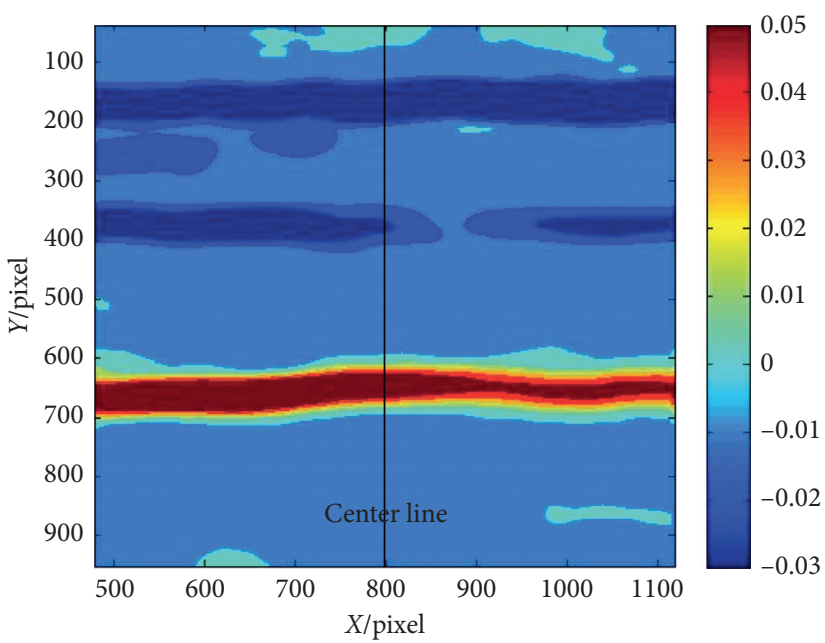

FIgURE 10: Vertical strain under $100 \%$ overload.

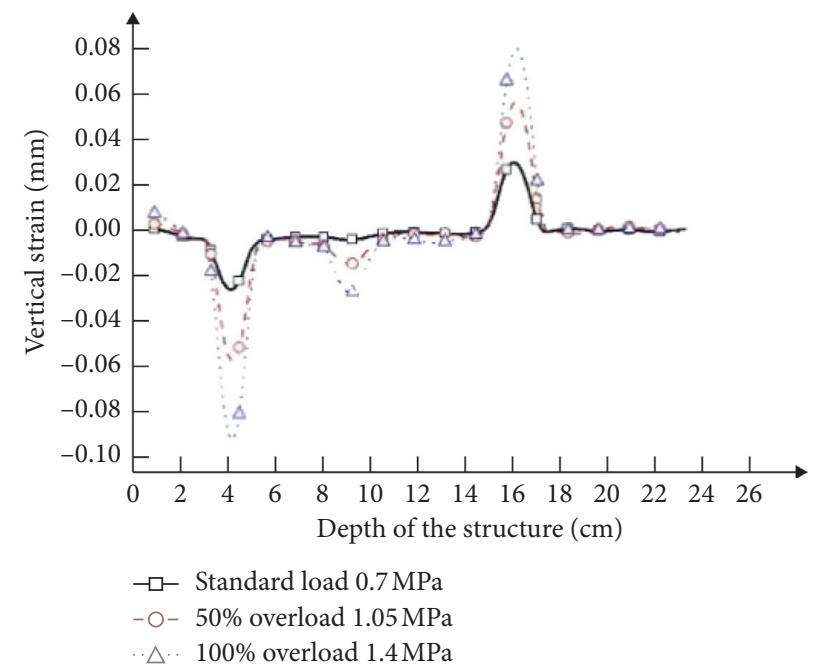

FIgURe 11: Vertical strain line of the center line. 
TABLE 4: Maximum vertical strain value of the asphalt layer bottom.

\begin{tabular}{|c|c|c|c|}
\hline Working condition & Bottom of the upper layer/ $\varepsilon$ & Bottom of the middle layer/ $\varepsilon$ & Bottom of the lower layer/ $\varepsilon$ \\
\hline Standard load & -0.0251 & -0.0033 & 0.0303 \\
\hline $50 \%$ overload & $\begin{array}{l}-0.0559 \\
122.71 \%\end{array}$ & $\begin{array}{l}-0.0139 \\
321.21 \%\end{array}$ & $\begin{array}{l}0.0570 \\
88.12 \%\end{array}$ \\
\hline $100 \%$ overload & $\begin{array}{l}-0.0907 \\
261.35 \%\end{array}$ & $\begin{array}{l}-0.0263 \\
696.97 \%\end{array}$ & $\begin{array}{c}0.0807 \\
166.33 \%\end{array}$ \\
\hline
\end{tabular}

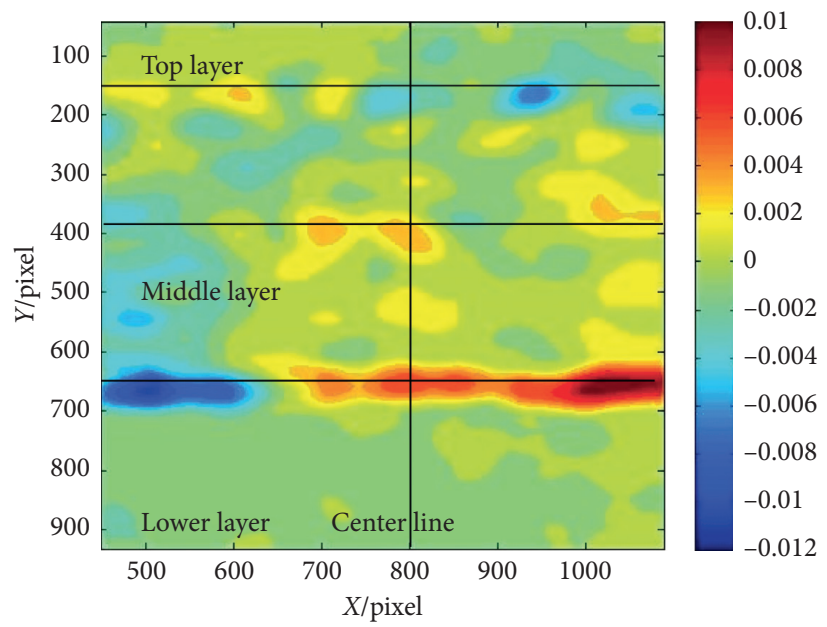

FIGURE 12: Shear strain under standard load.

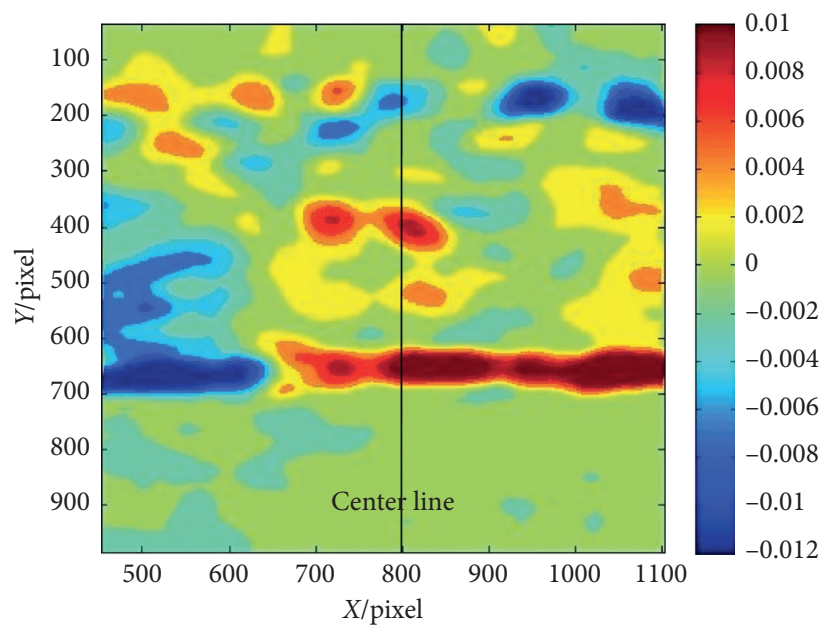

FIgURE 13: Shear strain under 50\% overload.

amplitude of the strain value in the above two locations is the most obvious with the increase of load. Taking 100\% overload as an example, the vertical compressive strain at the bottom of the upper layer of asphalt is 3.6 times of the standard load, and the tensile strain at the bottom of the lower layer of asphalt is 2.7 times of the standard load. Under different load conditions, the strain values and variation amplitude of each layer bottom are shown in Table 4. As can be seen from Table 4, the influence of overload on the stress state of pavement structure cannot be ignored.
4.3. Pavement Structure Shear Strain Analysis. Shear stress can lead to surface cracking, rutting, and sliding. Figures 12 14 show the distribution of shear stress of the pavement structure under different load conditions.

The shear strain data observed in Figures 12 14 are arranged, and the shear strain at the center line is selected for analysis, as shown in Figure 15.

From Figures 12 to 15 , it can be seen that (1) the phenomenon of shear strain concentration appears at the bottom of each layer of pavement structure, that is, the 


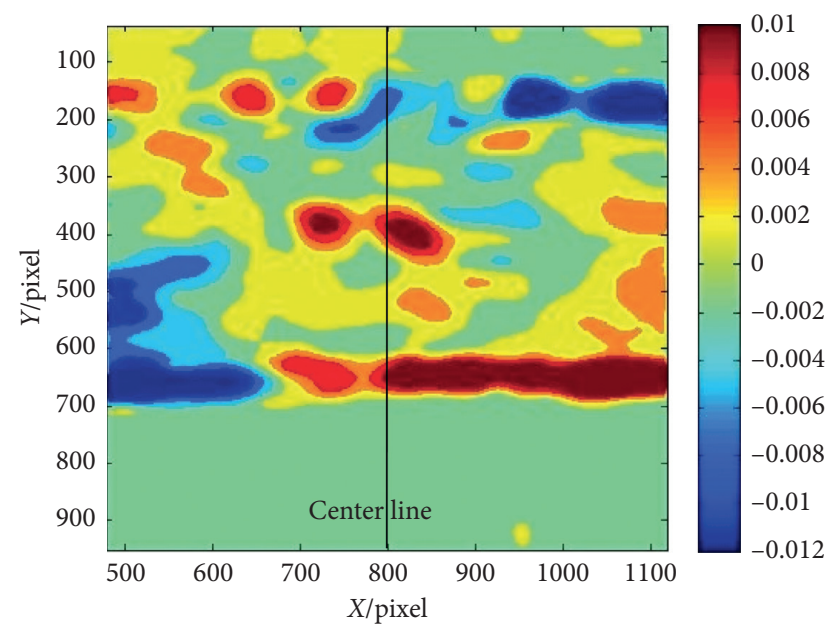

FIGURE 14: Shear strain under 100\% overload.

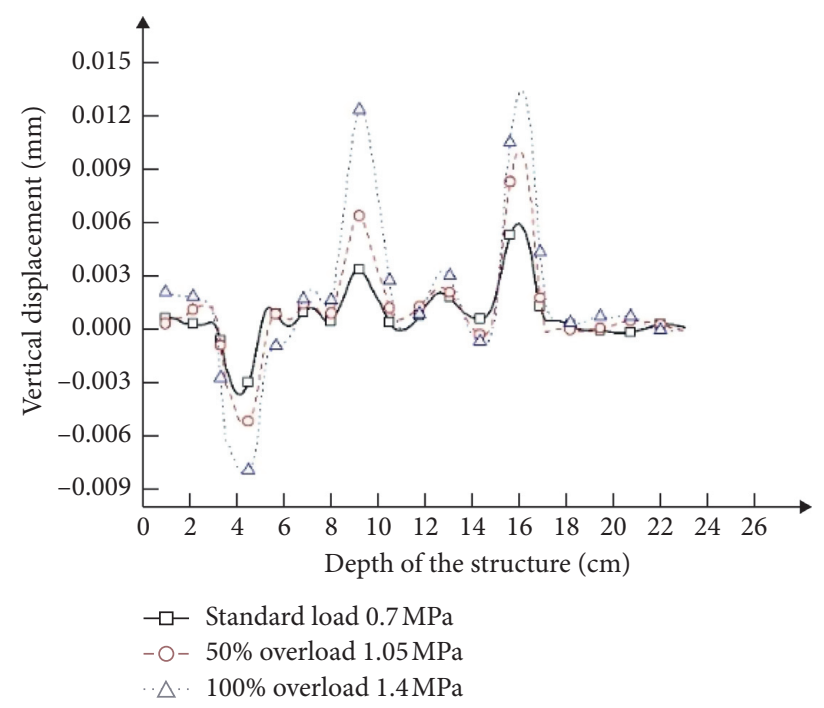

FIGURE 15: Shear strain line of the center line.

TABLE 5: Center line shear strain of the asphalt layer bottom.

\begin{tabular}{|c|c|c|c|}
\hline Working condition & Bottom of the upper layer $/ \varepsilon$ & Bottom of the middle layer/ $\varepsilon$ & Bottom of the lower layer/ $\varepsilon$ \\
\hline Standard load & -0.003768 & 0.003234 & 0.005789 \\
\hline $50 \%$ overload & $\begin{array}{c}-0.005441 \\
44.40 \%\end{array}$ & $\begin{array}{c}0.006221 \\
92.37 \% \\
\end{array}$ & $\begin{array}{c}0.009878 \\
70.63 \% \\
\end{array}$ \\
\hline $100 \%$ overload & $\begin{array}{c}-0.008164 \\
116.67 \%\end{array}$ & $\begin{array}{l}0.012155 \\
275.83 \%\end{array}$ & $\begin{array}{l}0.013278 \\
129.36 \%\end{array}$ \\
\hline
\end{tabular}

maximum shear strain of each layer appears at the bottom of the layer; (2) under the same load, the maximum shear strain occurs at the bottom layer of asphalt. This is caused by discontinuity between layers; (3) with the increase of load, the internal shear strain value of the pavement structure increases, and the most significant increase value of each layer bottom is between $44.40 \%$ and $275.83 \%$, as shown in Table 5.

\section{Conclusion}

(1) Digital speckle observation test method can accurately obtain the displacement value and stress-strain value of each layer of the pavement structure, and the application effect is good.

(2) The stress state of each layer of the pavement structure is greatly affected by the interlayer effect, 
and its influence cannot be ignored. The vertical displacement of each layer will be abrupt, and the strain concentration of tensile strain and shear strain will occur between layers.

(3) Overload seriously worsens the overall stress state of the pavement structure, among which the bottom of the asphalt upper layer, the bottom of the asphalt lower layer, and the top of the water-stabilized gravel layer are the most significant. Therefore, the structural design of heavy-duty road requires targeted research on the above parts.

\section{Data Availability}

The data used to support the findings of this study are included within the article.

\section{Conflicts of Interest}

The authors declare that they have no conflicts of interest.

\section{References}

[1] H. Liu, Y. Q. Tan, X. H. Song, and L. D. Zhao, "Influence of bonding condition between base and surface courses of asphalt pavement on pavement stress response," Journal of Highway and Transportation Research and Development, vol. 26, no. 3, pp. 1-6, 2009.

[2] U. Zhan, D. C. Fend, X. Z. Linu, and Q. L. Li, "Vertical coupling dynamics model of heavy truck-pavement-subgrade," China Journal of Highway and Transport, vol. 28, no. 4, pp. 1-12, 2015.

[3] H. L. Xu, Y. Yuan, T. J. Qu, and J. R. Tang, "Dynamic model for a vehicle-pavement coupled system considering pavement roughness," Journal of Vibration and Shock, vol. 19, no. 33, pp. 152-156, 2014.

[4] H. L. Xu, Z. C. He, and L. He, "Analysis on asphalt concrete pavement deformation characteristics time-domain considering vehicle-pavement coupling effect," Journal of Highway and Transportation Research and Development, vol. 34, no. 12, pp. 16-22, 2017.

[5] H. J. Gao, "Analysis of roadbed under traffic load based on dynamic finite element," Journal of Lanzhou Institute of Technology, vol. 20, no. 6, pp. 39-41, 2013.

[6] Y. Mao, P. Li, T. F. Nian, M. Lin, and X. Y. Wei, "Mechanical friction intensity behavior of asphalt pavement based on fractal theory," Journal of Jilin University: Engineering and Technology Edition, vol. 50, no. 2, pp. 594-605, 2020.

[7] X. Y. Zhou, J. T. Shi, and X. D. Wang, "Experimental study on interlayer strain transfer of semi-rigid base asphalt pavement and analysis on influencing factors," Journal of Highway and Transportation Research and Development, vol. 34, no. 6, pp. 1-6, 2017.

[8] X. D. Wang, "Design of pavement structure and material for full-scale test track," Journal of Highway and Transportation Research and Development, vol. 34, no. 6, pp. 30-37, 2017.

[9] Z. Y. Wu, Research on Cumulative Fatigue Damage of Asphalt Mixture and Asphalt Layer Based on Multi-Level Amplitude Loading, South China University of Technology, Guangzhou, China, 2014.

[10] S. B. Chen, Y. Q. Yuan, and Y. S. Yao, “Test on strengthening interlayer cohesion of semi-rigid base asphalt pavement by interlayer treatment," Journal of Chang'an University:Natural Science Edition, vol. 39, no. 4, pp. 44-51, 2019.

[11] S. F. Xu, D. Z. Zhu, and Z. Y. Wang, "Analysis on the influence of interlayer bonding conditions on cracking of heavy duty asphalt pavement," Highway, vol. 64, no. 8, pp. 1-7, 2019.

[12] S. Safavizadeh, A. D. Wargo, and Y. R. Kim, "Utilizing digital image correlation (DIC) in asphalt pavement testing," Journal of Testing and Evaluation, vol. 46, no. 3, 2017.

[13] E. Romeo and A. Montepara, "Characterization of reinforced asphalt pavement cracking behavior using flexural analysis," Procedia-Social and Behavioral Sciences, vol. 53, pp. 356-365, 2012.

[14] M. Bueno, J. Andrés, A. Treuholz, M. Arraigada, and M. N. Partl, "Digital image correlation to monitor cracking and induction healing of asphalt roads," in Proceedings of the 8th RILEM International Conference on Mechanisms of Cracking and Debonding in Pavements, Springer, Delft, Netherlands, May 2016.

[15] I. Yamaguchi, “A laser-speckle strain gauge," Journal of Physics E: Scientific Instruments, vol. 14, no. 11, pp. 1270-1273, 1981.

[16] W. H. Peters and W. F. Ranson, "Digital imaging techniques in experimental tress analysis," Optical Engineering, vol. 21, no. 3, pp. 427-431, 1982.

[17] J. Zhao, Research on Digital Speckle Correlation Method and its Applications in Mechanical Engineering Measurement, Beijing Forestry University, Beijing, China, 2014.

[18] Y. H. Wang, H. Liang, S. H. Wang, H. Zhang, and L. X. Yang, "Advance in digital speckle correlation method and its applications," Chinese Optics, vol. 6, no. 4, pp. 470-480, 2013.

[19] D. Q. Chen, Digital Speckle Correlation Technique and its Application in Monitoring Structure, Suzhou University, Suzhou, China, 2005.

[20] X. H. Li, Merchanical Response of Asphalt Pavement Under Different Contact Condition Among Interfacials, Chang'an University, Xi'an, China, 2012. 